\title{
A reflexão dos estudantes sobre a tarefa de elaborar questões de Física: um olhar ao longo do tempo
}

The students' reflection on the task of formulating Physics questions: an overview over time

\author{
Atos Edwin Pereira da Silva Lucas ${ }^{1}$ \\ Marta Maximo Pereira ${ }^{2}$
}

\section{Resumo}

Este artigo parte do pressuposto de que a metacognição pode ser desenvolvida na escola, por intermédio da mediação docente. Tem-se como objetivo investigar o modo como a atividade denominada "Elaboração e resolução reflexivas de questões pelos estudantes" influenciou no desenvolvimento da metacognição dos estudantes. Para tanto, estudantes de Ensino Técnico Integrado ao Ensino Médio, de uma instituição federal de ensino, realizaram tal atividade nos anos de 2014, 2015 e 2016, em aulas de Física. Foi desenvolvida uma pesquisa qualitativa com dados obtidos em entrevistas com alguns dos alunos. Conhecimentos metacognitivos e aspectos afetivos foram usados como embasamento teórico para a análise dos dados. Foi possível concluir que, mesmo conhecendo os critérios da tarefa e tendo tido a oportunidade de desenvolver estratégias para realizá-la ao longo das diferentes aplicações da atividade, a presença do conhecimento científico a ser abordado na questão é também um elemento central na realização da tarefa.

Palavras chave: metacognição; elaboração de questões; Física

\section{Abstract}

This paper is based on the assumption that metacognition can be developed at school, through teacher mediation. It aims to investigate how the activity called "Reflexive formulation and solution of questions by students", influenced the development of the students' metacognition. It was carried out with High School students at a federal educational institution in 2014, 2015 and 2016, during Physics classes a qualitative research was conducted considering data from interviews with some of the students. Metacognitive knowledge and affective aspects were used as theoretical framework. It was possible to conclude that even knowing the criteria of the task and having had the opportunity to develop strategies to carry it through the different applications of the activity, the presence of the scientific knowledge to be addressed in the question is also a central element in the accomplishment of the task.

Keywords: metacognition; formulation of questions; Physics

\footnotetext{
${ }^{1}$ Centro Federal de Educação Tecnológica Celso Suckow da Fonseca | atos.flum@gmail.com

${ }^{2}$ Centro Federal de Educação Tecnológica Celso Suckow da Fonseca | martamaximo@yahoo.com
} 


\section{Introdução}

No que diz respeito à aprendizagem de ciências, as perguntas podem ser a chave para o desenvolvimento cognitivo e para uma real apropriação de conhecimento, e não apenas para a ativação de uma memória recente, que em poucos dias não mais existirá. De acordo com Márquez e Roca (2006), é importante ensinar aos estudantes como elaborar problemas e fazer perguntas, para que eles possam se engajar na cultura científica.

Além disso, é fundamental que os alunos reflitam acerca de suas potencialidades e dificuldades e de como se dá o seu processo de aprendizagem, ou seja, que desenvolvam sua metacognição (FLAVELL, 1987). Faz-se essa consideração porque o conhecimento sobre o que se sabe ou não e sobre formas mais adequadas de se aprender determinado assunto pode auxiliar os estudantes a superarem dificuldades de aprendizagem (ABIB, 2010). Ademais, Gomes e Almeida (2016, p. 54) afirmam que "O fato de os alunos poderem controlar e gerir os próprios processos cognitivos Ihes dá a noção da responsabilidade pelo seu desempenho escolar e gera confiança nas suas próprias capacidades".

Rosa e Pinho-Alves (2012, p. 7) apontam, em seu trabalho, para a "necessidade de que o professor estabeleça situações didáticas de evocação explícita do pensamento metacognitivo, ultrapassando o entendimento dessa evocação como algo espontâneo nos estudantes". Convergindo com esse entendimento, foi proposta por MaximoPereira e Andrade (2014) a atividade "Elaboração e resolução reflexivas de questões pelos estudantes", que visa proporcionar a reflexão dos alunos sobre sua aprendizagem por intermédio da elaboração de questões por eles mesmos. Nesse trabalho, as autoras analisaram, no contexto de aulas de Física, (1) a questão elaborada por uma aluna de Ensino Médio; (2) a resposta dada por ela e (3) sua justificativa para a elaboração da pergunta. Já em Carvalho e Maximo-Pereira (2016), foram analisados dados coletados em uma turma de 46 estudantes, que realizou a mesma atividade em 2014, também em aulas de Física. Ambos trabalhos apontam para as potencialidades da atividade no que se refere à explicitação de conhecimentos metacognitivos pelos estudantes.

No presente artigo, deseja-se investigar o modo como a atividade "Elaboração e resolução reflexivas de questões pelos estudantes" influencia, ao longo do tempo, o desenvolvimento da metacognição por parte dos alunos. Para tanto, analisamos entrevistas feitas com estudantes que realizaram a atividade mencionada ao longo de três anos consecutivos. Os conhecimentos metacognitivos e os aspectos afetivos foram considerados como elementos teóricos para a análise de dados.

\section{Fundamentação teórica}

Algumas pesquisas internacionais em psicologia (EFKLIDES, 2006) já apontam para relações entre metacognição e afetividade. Faz-se a defesa, neste artigo, que área de ensino de ciências pode se valer dessa aproximação em suas pesquisas, como forma de aprofundar e complexificar a análise dos processos de ensino e aprendizagem escolar de ciências. Assim, o embasamento teórico deste trabalho se justifica como forma de contribuir para estudos que associam os aspectos metacognitivos e afetivos.

Etimologicamente, a palavra metacognição significa "para além da cognição, ou seja, a faculdade de conhecer o próprio ato de conhecer" (RIBEIRO, 2003, p. 109). Na década de 1970, com os trabalhos de Flavell $(1976,1979)$ na área do desenvolvimento cognitivo e da 
memória, iniciam-se os estudos sobre os processos metacognitivos que coordenam as aptidões cognitivas envolvidas na memória, leitura, compreensão de textos, etc. $O$ interesse pela metacognição na educação, para Figueira (2003, p. 14), é devido ao fato

[...] de se ter demonstrado que esta variável desempenha um papel de primordial importância em áreas fundamentais da aprendizagem escolar, nomeadamente, na resolução de problemas, na compreensão e comunicação oral e escrita.

Para Flavell, Miller e Miller (1999), a metacognição é definida de forma ampla como sendo o conhecimento ou atividade cognitiva que toma como seu objeto a cognição ou que regula qualquer aspecto da iniciativa cognitiva. Para os mesmos autores, a metacognição se refere tanto ao conhecimento metacognitivo (ou metaconhecimento) como ao monitoramento e à autorregulação cognitivos. Neste trabalho, a análise de dados está baseada apenas nos conhecimentos metacognitivos.

O conhecimento metacognitivo é o conhecimento dos próprios recursos cognitivos. Ele subdivide-se em três dimensões: conhecimento sobre pessoas, sobre tarefas e sobre estratégias.

A primeira delas, segundo com Figueira (2003, p. 3), diz respeito ao "conhecimento ou crença que a pessoa tem de si enquanto ser cognitivo, em tarefas cognitivas diversas, sobre os fatores ou variáveis que atuam ou interagem e de que maneiras afetam os resultados dos procedimentos cognitivos". Refere-se a "convicções que os estudantes apresentam sobre si e em comparação com os outros" (PASSOS; CORRÊA; ARRUDA, 2017, p. 179). A dimensão das tarefas tem relação com o conhecimento que o sujeito tem sobre a natureza, as exigências e os critérios da atividade que irá realizar. Já o conhecimento sobre as estratégias se relaciona com o conhecimento sobre os meios mais prováveis para se alcançar os objetivos cognitivos (FLAVELL; MILLER; MILLER, 1999).

Os mesmos autores consideram o metaconhecimento como interações ou combinações entre essas dimensões. Por exemplo, o metaconhecimento sobre tarefas pode auxiliar na elaboração do metaconhecimento sobre estratégias, na medida em que a identificação do nível de exigência da tarefa aponta para a necessidade de que o indivíduo desenvolva formas para realizá-la, a fim de atingir seus objetivos de aprendizagem.

Ao refletirem sobre seus processos cognitivos, o que leva os indivíduos a atribuírem a um dado acontecimento ou característica (do ensino ou do próprio estudante) sua facilidade ou dificuldade para aprender? Entende-se que elementos afetivos influenciam sobremaneira a aprendizagem, pois os estudantes são afetados de diferentes modos por suas relações com os outros colegas, com o professor, com as atividades propostas e com o conhecimento científico escolar.

Faz-se essa afirmação concordando com Vigostki (2009), que critica a separação entre as dimensões cognitiva e afetiva do funcionamento psicológico. $\bigcirc$ autor adota uma abordagem unificadora entre elas:

[...] Quem separou desde o início o pensamento do afeto fechou definitivamente para si mesmo o caminho para a explicação das causas do próprio pensamento, porque a análise determinista do pensamento pressupõe necessariamente a revelação dos motivos, necessidades, interesses, motivações e tendências motrizes do pensamento, que the orientam o movimento nesse ou naquele aspecto. (VIGOTSKI, 2009, p. 16, grifo nosso) 
Ainda que, segundo Arantes (2003, p. 7), o tema da afetividade seja "raramente abordado e frequentemente ocultado nas encruzilhadas do cotidiano escolar", torna-se relevante, para este estudo, o conceito de afetividade enquanto elemento que reflete as influências das relações interpessoais nas singularidades de cada sujeito em seu processo de aprendizagem. Para Mahoney e Almeida (2005, p. 1), a "[...] afetividade refere-se à capacidade, à disposição do ser humano de ser afetado pelo mundo externo/interno sempre acompanhado de sensações ligadas a tonalidades agradáveis ou desagradáveis".

Maximo-Pereira (2014) estabelece duas classificações para as relações afetivas estabelecidas pelos estudantes com uma situação ou conhecimento: relações afetivas positivas são aquelas que auxiliam a aprendizagem; já relações afetivas negativas ocorrem sempre que a relação estabelecida é tal que não colabora para a aprendizagem do aluno.

\section{Metodologia}

A pesquisa realizada tem caráter qualitativo (MOREIRA; CALEFFE, 2006) e analisou dados de entrevistas feitas com alunos selecionados dentre aqueles que realizaram a atividade "Elaboração e resolução reflexivas de questões pelos estudantes" em três anos consecutivos. Nessa atividade, eles foram solicitados a elaborar uma questão de Física com o conhecimento que adquiriram durante o ano letivo ou de anos anteriores, já que essa atividade foi proposta no fim do ano. Além disso, tinham a tarefa de resolver tal questão e também explicar a escolha do assunto e da forma da mesma, ou seja, deviam fornecer uma justificativa para a elaboração da questão.

Essa atividade foi realizada em 2014, 2015 e 2016, em aulas de Física, por alunos de Ensino Técnico Integrado ao Ensino Médio de uma instituição federal de ensino. Os estudantes cursavam o $1^{\circ}$ ano em 2014, o $2^{\circ}$ ano em 2015 e o $3^{\circ}$ ano em 2016. No $1^{\circ}$ ano, 46 alunos fizeram a atividade; no $2^{\circ}$ ano, 23; no $3^{\circ}$ ano, 16.

Os alunos escolhidos para a entrevista deveriam ter feito a tarefa em todos os três anos. É importante registrar que os estudantes investigados tiveram aulas de Física regulares somente no $1^{\circ}$ e $2^{\circ}$ anos e que a coleta de registros no $3^{\circ}$ ano ocorreu em horário extra, por intermédio de convite para participarem da pesquisa.

Em trabalhos anteriores (CARVALHO; MAXIMO-PEREIRA, 2016), a análise das questões elaboradas e de suas respectivas respostas deu origem à seguinte classificação: QC para questões corretas, QPC para questão parcialmente correta, ou seja, com algum erro que não impossibilitava sua resolução, e QI para questões incorretas. Já as respostas foram classificadas como: RC para respostas corretas, RPC para respostas parcialmente corretas, ou seja, com alguma incorreção, e Rl para respostas incorretas, isto é, que apresentavam incorreções que impossibilitavam o atendimento ao enunciado. A escolha dos sujeitos entrevistados, dentre os 16 alunos que realizaram a atividade nos três anos, se deu com base nessas classificações e também no assunto da questão escolhido por cada aluno.

Haguette (1997, p. 86) define a entrevista como um "processo de interação de duas pessoas na qual uma delas, o entrevistador, tem por objetivo a obtenção de informação por parte do outro, o entrevistado". Foram realizadas com os estudantes entrevistas individuais semiestruturadas. Elas são feitas com base em perguntas abertas e/ou fechadas, por intermédio das quais o informante tem a possibilidade de discorrer sobre o tema proposto. Há algumas questões definidas previamente, porém o pesquisador faz as perguntas em um contexto muito semelhante ao de uma conversa informal. Além disso, dependendo do que 
o entrevistado diga, o entrevistador pode fazer perguntas extras, diferentes das previstas inicialmente, sendo bem flexível e permitindo, em geral, bons resultados.

Foram selecionados para a entrevista os Alunos 9 e 10 e a Aluna 32. O Aluno 9 foi escolhido porque abordou em suas questões o mesmo assunto em 2014 e 2016 (Forças e Leis de Newton), tendo passado da condição de QI + RPC em 2014 para QC + RC em 2016, o que parece evidenciar uma evolução tanto na elaboração das questões quanto na resolução das mesmas. Tal fato levou ao estudo desse caso com maior especificidade e profundidade.

O Aluno 10 foi escolhido por demonstrar domínio de diversos assuntos dentro da matéria, visto que, em cada ano de atividade, elaborou uma questão com um assunto diferente do que havia usado no ano anterior (Trabalho em 2014, Eletrostática em 2015 e Energia em 2016). Além de utilizar diversas temáticas da Física estudadas ao longo dos anos, ele também obteve QC + RC nos três anos de atividade, mostrando uma linearidade interessante no que diz respeito a seus resultados.

Já a Aluna 32 também abordou o mesmo assunto (Trabalho) em suas questões de 2014 e 2106. No entanto, diferentemente do Aluno 9, ela apresentou QI + RPC nesses dois anos de atividade, o que também a tornou um sujeito interessante para ser investigado por intermédio da entrevista e da análise da questão que elaborou de forma incorreta nos dois anos.

A entrevista foi realizada a fim de que fosse possível entender como eles percebiam e avaliavam todo o processo de realização das atividades ao longo dos anos e para que fosse possível fazer inferências sobre suas aprendizagens e o desenvolvimento da metacognição. Foram utilizadas as seguintes perguntas gerais:

(1) Você se lembra da atividade que fez no $7^{\circ}$ ano, em que tinha que elaborar uma questão, resolvê-la e justificar a elaboração dela?

(2) Você lembra qual foi o conteúdo da questão que elaborou no $7^{\circ}$ ano? E seu desempenho na atividade?

(3) E no $2^{\circ}$ e $3^{\circ}$ anos, você se lembra do que fez nas atividades e quais foram os seus desempenhos nelas, respectivamente?

(4) Qual foi o grau de dificuldade de realização da atividade durante os três anos? Fácil, regular, difícil ou isso foi mudando ao longo do tempo? Se mudou, como mudou? Se

mudou, o que você acha que contribuiu para mudar o grau de dificuldade da tarefa?

Em seguida, cada aluno foi apresentado às questões, resoluções e justificativas que elaborou em 2014, 2015 e 2016, respectivamente. Por último, foram feitas perguntas mais específicas, elaboradas de acordo com o perfil de cada sujeito nas atividades. Apenas o Aluno 10 e a Aluna 32 realizaram a entrevista. A análise que apresentamos neste trabalho considerou as falas do Aluno 10 e as questões elaboradas pela Aluna 32 em 2014 e 2016.

\section{Análise de dados}

O Aluno 10, que ao ser questionado se lembrava o conteúdo das questões elaboradas por ele, respondeu da seguinte maneira: 
Aluno 10: Lembro, no primeiro ano, que o tema foi deslocamento e distância; no segundo ano, eu fiz sobre força e no terceiro, por mais que seja recente, eu não faço ideia. O primeiro é o mais claro.

A partir dessa resposta, pode-se inferir que o primeiro ano em que realizou a atividade parece ter sido mais marcante para o estudante. Fazemos tal inferência considerando que ele afirmou também ter gostado da atividade, pois, além de ser uma tarefa diferente das que costumava realizar na escola, por intermédio dela ele pôde conhecer melhor uma das coisas que os professores fazem o tempo todo (elaborar questões):

Aluno 10: Olha, eu acho muito legal porque a gente não tem costume de elaborar questões e sempre pedimos ao professor para fazer uma lista, certo? Só que não pensamos que ele tem que elaborar, observar se as questões estão no nível dos alunos e se eles estão entendendo a explicação, então, quando a gente sente na pele o que é isso, de ter que escolher um tema e elaborar uma questão, a gente acaba entendendo melhor como é a vida de um professor.

Ao ser questionado sobre o grau de dificuldade da tarefa realizada ao longo dos três anos, o aluno disse que teve maior dificuldade durante o primeiro ano, por nunca antes ter elaborado questões; no segundo, disse que foi mais fácil e, no terceiro, como afirmou estar há um ano sem contato com a matéria, ele voltou a sentir mais um pouco de dificuldade ao elaborar questões.

Pelo seu relato, ter feito a atividade em 2014 ajudou-o a realizá-la com mais facilidade em 2015, ou seja, conhecer os critérios da tarefa solicitada, desenvolvendo o conhecimento metacognitivo sobre tarefas, parece dar-Ihe a possibilidade de realizá-la de forma mais segura e consciente, o que pode ser importante para seu sucesso nela. No entanto, no último ano em que fez a atividade, mesmo já sendo a terceira oportunidade de contato com essa tarefa, o aluno voltou a sentir dificuldade para realizá-la. Ele atribuiu tal dificuldade ao fato de não ter tido aula de Física em 2016. Isso é uma evidência de que, mesmo conhecendo os critérios da tarefa e tendo tido a oportunidade de desenvolver estratégias para realizá-la ao longo das duas aplicações anteriores, a presença do conhecimento a ser abordado na questão é também um elemento central na realização da tarefa. Em outras palavras, os aspectos cognitivos e metacognitivos parecem constituir de forma indissociável a realização da atividade proposta.

Ao tentarmos traçar um perfil do aluno no que se refere às suas percepções sobre o seu domínio da tarefa e do conteúdo ao longo dos 3 anos, ele explicitou que, em 2014, sabia o conteúdo de Física, mas tinha baixo domínio da tarefa; em 2015, ele dominava tanto a realização da tarefa como o assunto relativo a ela; em 2016, o estudante acreditou ter um baixo domínio do conteúdo, pelo tempo sem contato com a matéria de Física, porém conseguiu realizar a tarefa de forma satisfatória.

Convém ressaltar que esta foi a percepção do próprio estudante em relação aos três anos de atividade, que está ilustrada por intermédio do Gráfico 1. Ainda que tal gráfico possa ser uma representação bastante simplificada de como as percepções dele vão se transformando ao longo do tempo e do contato com a atividade, o reconhecimento desse processo, feito por intermédio do que o aluno expressa em sua entrevista, parece ser uma evidência do desenvolvimento da metacognição por parte dele. Concordamos com Passos, Corrêa e Arruda (2017, p. 177) quando afirmam que "ao estudar e estar consciente de como 
se conseguiu aprender determinados conteúdos, reconhecendo os fatores que corroboraram e os que dificultaram certa aprendizagem, é que se constroem caminhos para a apropriação do próprio aprendizado".

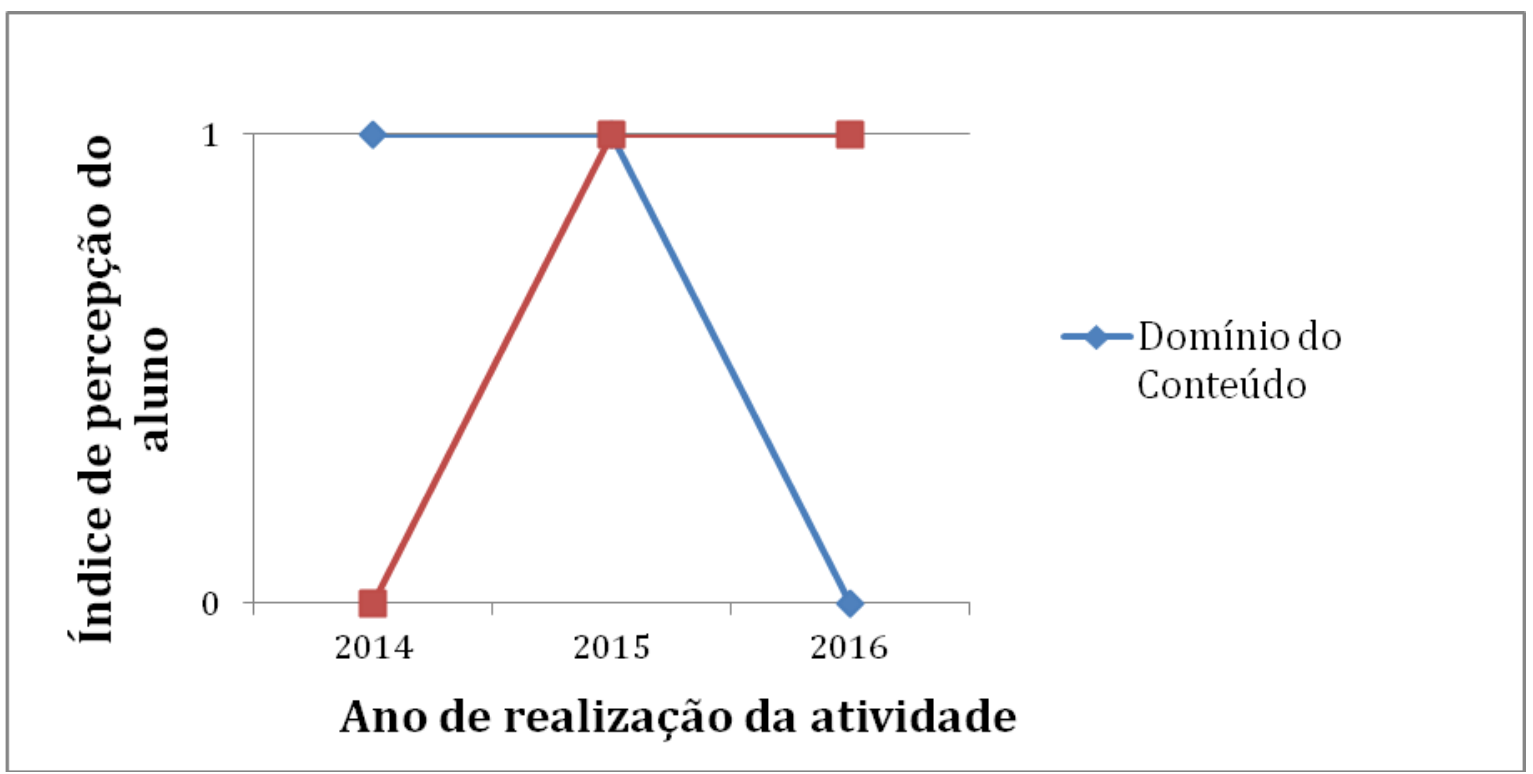

Gráfico 1. Percepções do Aluno 10 sobre seu domínio da tarefa e do conteúdo de Física utilizado na atividade ao longo do tempo.

No entanto, em termos somente do desempenho que o Aluno 10 apresentou na atividade, expresso no que efetivamente fez nos três anos ( $Q C+R C$ ), foi possível, na perspectiva dos pesquisadores, elaborar o Gráfico 2.

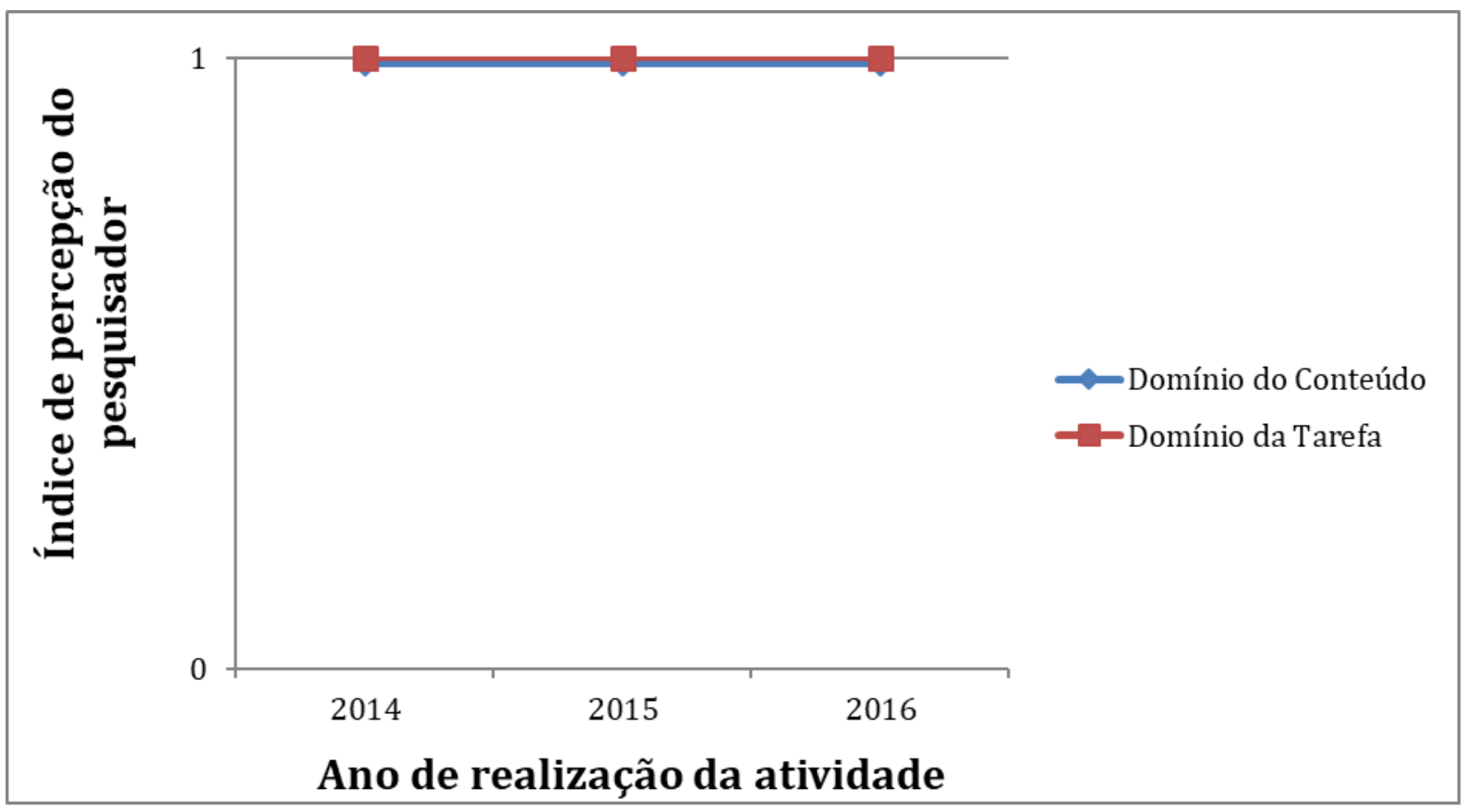

Gráfico 2. Percepções dos pesquisadores sobre o domínio da tarefa e do conteúdo de Física do Aluno 10 utilizado na atividade ao longo do tempo. 
É interessante lembrar que as percepções do Aluno 10 foram mencionadas antes de que as questões que ele elaborou e resolveu lhe fossem apresentadas na entrevista. Assim, essa diferenciação entre o resultado do aluno e sua percepção sobre o que fez indica aspectos interessantes.

Um primeiro deles é considerar que, tanto na pesquisa em ensino como na sala de aula, é importante considerar as relações entre o que o estudante faz e apresenta como resultado e a sua percepção sobre isso. Em outras palavras, a voz do sujeito que é analisado ou do aluno cujo desempenho é avaliado são aspectos que devem ser considerados para uma compreensão mais ampla dos complexos processos que se desencadeiam ao longo de sua aprendizagem.

Além disso, é relevante perceber a influência do aspecto temporal na elaboração dos Gráficos 1 e 2 e no processo de desenvolvimento da metacognição. Enquanto o Gráfico 2 foi elaborado considerando os dados de 2014, 2015 e 2016 do Aluno 10, o Gráfico 1 foi construído com base nas reflexões que o estudante fez no tempo presente, no momento da entrevista (2017), em relação ao passado. Isso significa que as percepções sobre domínio do conteúdo e da tarefa expressas pelo Aluno 10 já são o seu olhar recursivo sobre o seu processo de aprendizagem e de apropriação da tarefa, que eventualmente pode não mais coincidir com suas percepções do momento em que realizou cada uma das atividades. Em outras palavras, a diferenciação entre os Gráficos 1 e 2 pode indicar que o indivíduo transformou as suas percepções sobre seus processos cognitivos ao longo do tempo (o que pode ser um indicador de desenvolvimento da metacognição) ou que, mesmo que já tivesse tais percepções, conseguiu ter um bom desempenho na tarefa nos três anos por intermédio de estratégias e de relações que não explicitou até esse momento de sua fala. Tal fato é corroborado pela seguinte citação de Passos, Corrêa e Arruda (2017, p. 178):

Quando Flavell (1971) relaciona os processos mentais da memória à cognição, demonstra que o indivíduo evolui a partir da infância, apresentando relevantes mudanças em seu comportamento, principalmente no que diz respeito ao conhecimento conceitual e às habilidades cognitivas, uma vez que a mente humana sabe mais e pensa melhor à medida que envelhece, e, essas mudanças, quando consideramos o que o sujeito sabe e como pensa, têm efeitos sobre o que aprende e se lembra, como aprende e se lembra, e quando deve aprender e se lembrar.

Seguindo com a análise, ao longo da entrevista, o aluno não economizou elogios à professora que lecionou Física para sua turma em 2014 e 2015, chegando a dizer que odiava Física antes de ter contato com ela. Quando perguntado sobre os fatores que podiam ter contribuído para seu bom desempenho na atividade em seus três anos de realização, o aluno deu a seguinte resposta:

Aluno 10: Ah, sei lá, para falar a verdade, a professora [...] revolucionou a minha vida, porque eu odiava muito Física, nunca achei interessante, mas, no primeiro ano, quando eu a conheci, uma professora muito rígida, certinha e que explica muito bem, eu comecei a achar Física uma matéria maravilhosa. Falo isso pra todo mundo, porque achei que a matéria ficou muito mais legal e muito mais interessante, então aí eu passei a prestar mais atenção, logo, encontrei facilidade nos conteúdos. 
Com essa resposta, percebe-se que o aluno não atribuiu o seu bom desempenho a nenhuma característica específica da mesma, nem a uma possível familiaridade que poderia ter desenvolvido em relação a ela (no âmbito do conhecimento metacognitivo sobre tarefas e estratégias), nem diretamente a seu conhecimento sobre Física. Ao iniciar a sua resposta, o aluno falou sobre como as características da perspectiva de ensino da professora que ministrou as aulas em 2014 e 2015 ("muito rígida, certinha e que explica muito bem") haviam alterado a sua relação inicial com a Física e a sua percepção sobre a matéria (de "odiava muito Física, nunca achei interessante" para "eu comecei a achar Física uma matéria maravilhosa. [...] a matéria ficou muito mais legal e muito mais interessante"). Tais fatos foram usados por ele para justificar a sua postura nas aulas ("então aí eu passei a prestar mais atenção"), que parece ter influenciado o seu desempenho na disciplina ("logo, encontrei facilidade nos conteúdos").

Esse detalhamento do processo de aproximação do Aluno 10 em relação ao conhecimento de Física, com o estabelecimento de muitas relações, parece ser algo já bem estabelecido para o aluno, e não provocado apenas pela entrevista feita, pois, de acordo com ele "Falo isso pra todo mundo". Tal fato parece ser mais uma evidência de desenvolvimento da metacognição por parte do aluno, expresso não só no momento da entrevista, mas também em momentos anteriores.

Além disso, o aluno parece ter estabelecido uma relação afetiva positiva com a professora e suas práticas em sala de aula, pois ele atribuiu a isso a sua mudança de postura para com a disciplina, o que, a seu ver, contribuiu para que ele tivesse facilidade para aprender os assuntos ministrados. Concordamos com Efklides (2006, p. 8), quando afirma que "afeto positivo, por um lado, ameniza o esforço feito pela pessoa e, por outro lado, aumenta o interesse e o sentimento de vinculação, apoiando, desse modo, engajamentos futuros na mesma atividade ou em atividades similares".

Ainda de acordo com suas respostas, foi possível identificar que ele possui consciência sobre suas dificuldades e sabe identificá-las. Faz-se essa consideração porque lhe foi feita a seguinte pergunta: "As suas questões, como nós podemos observar, não têm muitos cálculos. Tem alguma razão para você ter elaborado questões mais conceituais, com diagrama e tudo mais?". O estudante forneceu a seguinte resposta:

\begin{abstract}
Aluno 10: Pois é, como vocês podem perceber, eu sou muito visual, por exemplo, eu coloquei esquema em todas, ou seja, eu lembro dos desenhos dados em sala. Agora, em relação às fórmulas, por mais que a professora explique e coloque-as no quadro, é uma coisa mais matemática, então, eu já tenho mais dificuldades, o conceitual para mim é mais interessante que as fórmulas.
\end{abstract}

A fala do aluno parece indicar que ele apresenta conhecimento metacognitivo sobre pessoas bastante desenvolvido, pois foi capaz de reconhecer muito bem seus pontos fortes e fracos e parece saber como utilizá-los. É possível fazer essa inferência porque o aluno elaborou exatamente questões que considerava ter mais facilidade para responder (questões mais conceituais, sem fórmulas e com muitos aspectos visuais). Em outras palavras, a percepção que desenvolveu sobre si e suas características o levou a desenvolver estratégias para elaborar questões de forma a contemplar as suas potencialidades, visando atender à demanda da tarefa (elaborar e resolver corretamente a questão). Vê-se, nesse exemplo, a interação entre os conhecimentos metacognitivos sobre pessoas, estratégias e 
tarefas sendo explicitada pelo Aluno 10, o que pode também ajudar a explicar o seu ótimo desempenho nos três anos em que realizou a atividade.

Passando à análise da Aluna 32, ela manteve o mesmo conteúdo (Trabalho) em suas questões do $1^{\circ}$ e do $3^{\circ}$ ano. Pelas respostas que elaborou para as questões (Figuras 1 e 2), é possivel identificar que ela possuía um domínio do conhecimento de que o trabalho de uma força perpendicular ao deslocamento é nulo, o que parece sugerir certa apropriação desse conhecimento quando o mesmo lhe foi apresentado ( $1^{\circ}$ ano) e após 2 anos ( $3^{\circ}$ ano), sendo este último sem aulas de Física. No entanto, em 2014, na Figura 1, a estudante usou o conceito de trabalho, expresso por sua relação matemática, de forma correta inicialmente e de forma incorreta no segundo cálculo que realizou.

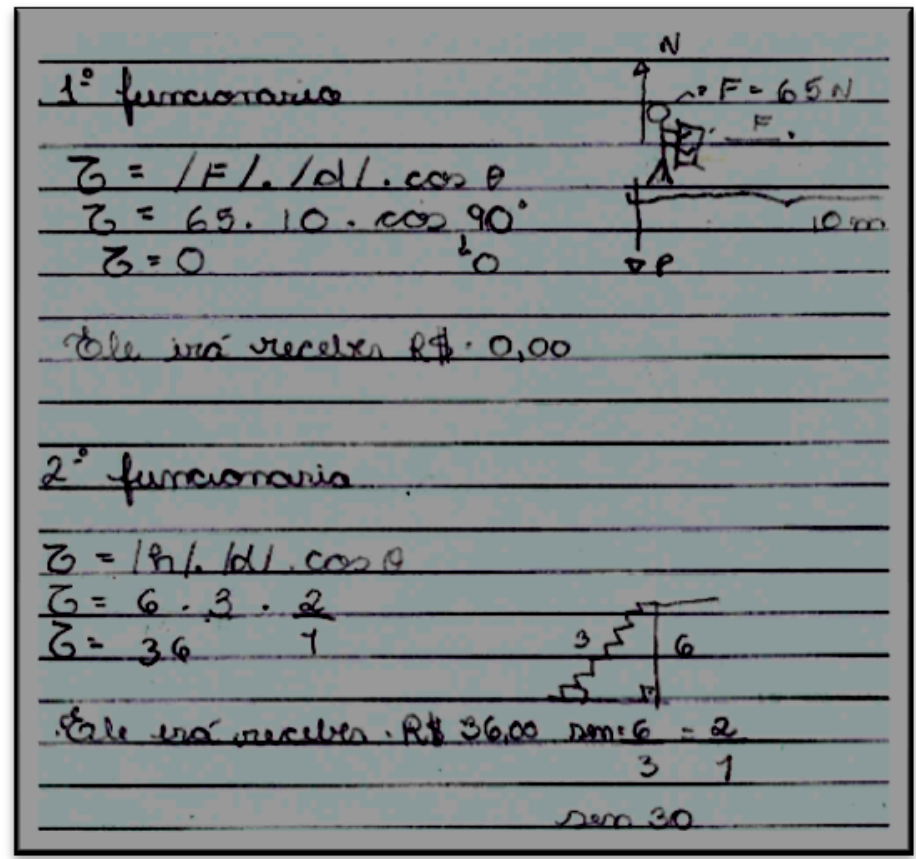

Figura 1. Resposta da Aluna 32 à questão que elaborou em 2014.

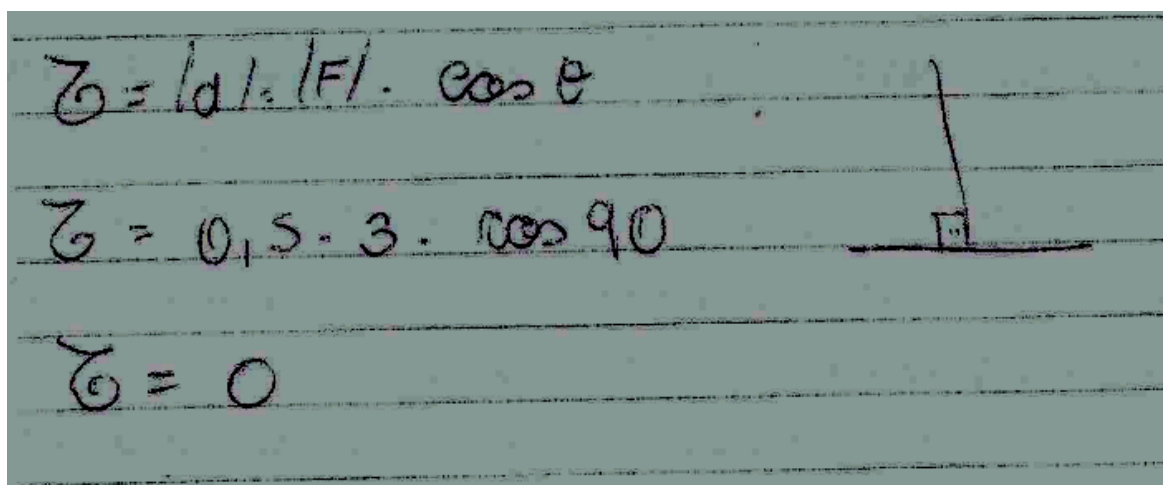

Figura 2. Resposta da Aluna 32 à questão que elaborou em 2016.

As questões elaboradas pela aluna, em 2014 e em 2016, para essas respostas que fornece, são bem semelhantes entre si (Figuras 3 e 4). 
Erm uma obra foram contratados doirs pedvei ros sendo que um pedreiro ficcue seupervisonando a Obra e a Qutro fucceu carreganda sacos de cimento. Savendo-se que os Reidecería que. fucair coupregando cessacos de cimento se deslocau $10 \mathrm{~m}$ \& aplecau uma força de $65 \mathrm{~N}$ para carregon a cimento is ma local que ele se deslacau íuma ársa plana carcule a traba lha deles sabl se que a cara que frocer sur perres manda subiu em uma escada de $6 \mathrm{~m}$ de altiripa is destacan $3 \mathrm{~m}$ ealcule ce travalha do segenda pedreirce. () chrefe ira pagar os surfuncionarios de acorda oom a que eles trabahenaram, quanto cada um brai receber?

Figura 3. Questão elaborada pela Aluna 32 em 2014, classificada como QI.

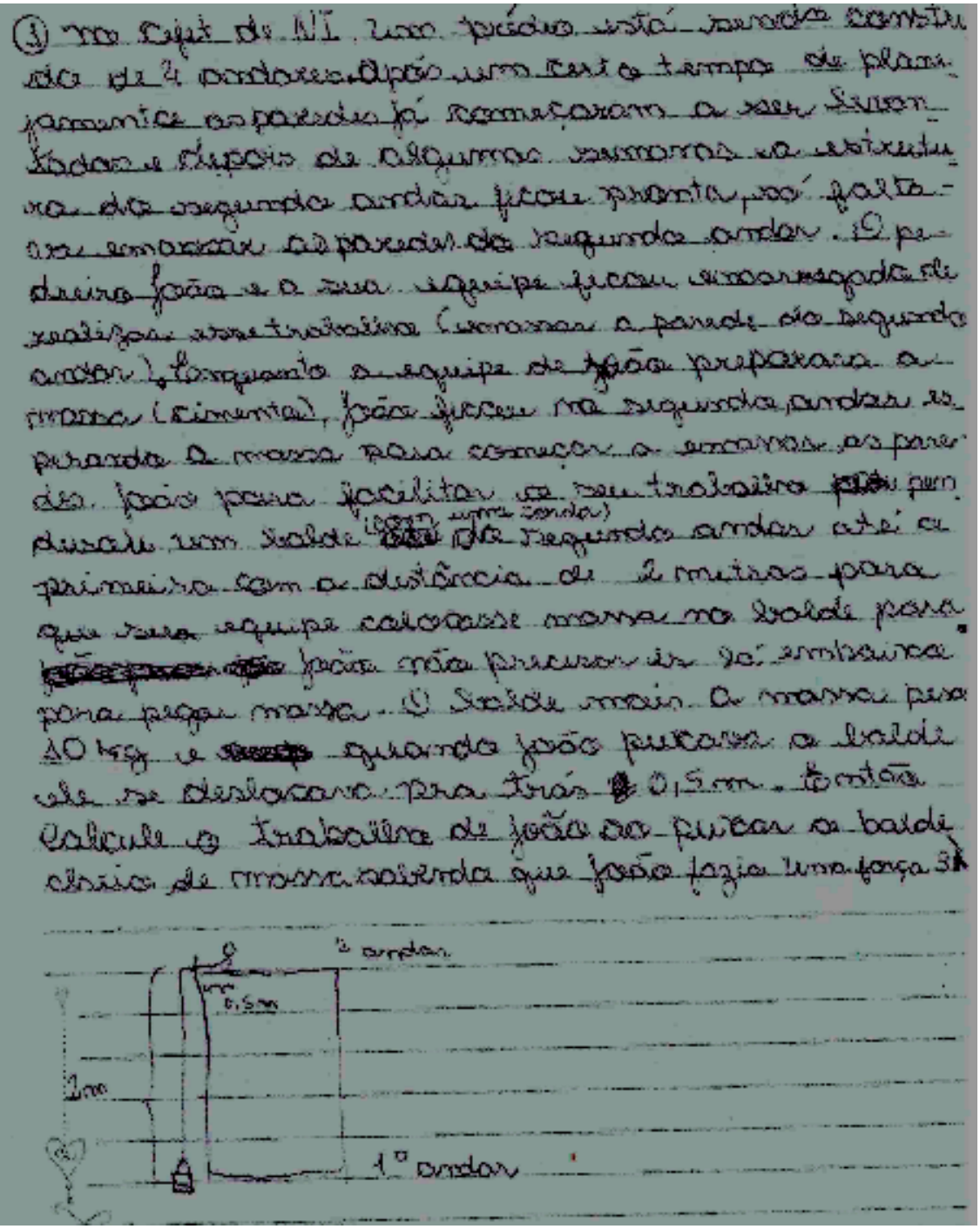

Figura 4. Questão elaborada pela Aluna 32 em 2016, classificada como QI. 
Em ambas há a presença de situações cotidianas similares (elevação de sacos de cimento em uma obra e de baldes de cimento para a construção de um prédio de 4 andares no CEFET/RJ Nova Iguaçu, que está realmente ocorrendo); falta de dados ou informações que possibilitem a resolução da questão; erros nos valores das medidas utilizadas, que também impossibilitam a resolução da questão. De forma geral, ela não conseguiu elaborar um enunciado em que o conceito de trabalho (ou de trabalho nulo para uma força perpendicular ao deslocamento) fosse adequadamente utilizado para a resolução da questão.

Ao ser indagada, na entrevista, sobre por que elaborou questões similares nos dois anos, a Aluna 32 afirmou que realmente tentou elaborar suas questões em torno do conhecimento sobre Trabalho, do qual, segundo ela, mantinha uma grande noção. As justificativas dadas pela estudante em 2014 e 2016 (Figuras 5 e 6) para a elaboração de suas questões são bem simplificadas, pois ela expressa ter se identificado ou gostado da matéria e, por isso, ter tido facilidade em aprender. Tais afirmações parecem estar de acordo com a percepção atual (2017) da Aluna 32, o que evidencia o estabelecimento de uma relação afetiva com esse conhecimento, ainda que ela não tenha explicitado o que a levou a estabelecer tal relação.

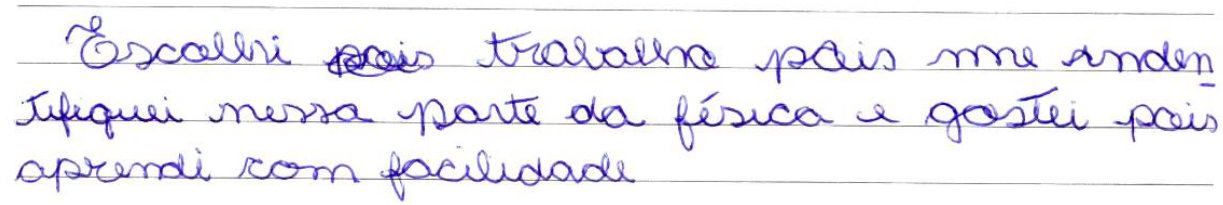

Figura 5. Justificativa da Aluna 32 para a elaboração de sua questão em 2014.

\section{Porque goote dessa materia}

Figura 6. Justificativa da Aluna 32 para a elaboração de sua questão em 2016.

Por tudo isso, entendemos que a Aluna 32 parece ter dificuldade de elaborar questões envolvendo determinado conteúdo, no âmbito do conhecimento metacongitivo sobre tarefas, por mais que possa ter se apropriado do conhecimento. Isso é uma evidência de que o domínio do conteúdo não necessariamente implica no domínio da tarefa, o que reforça a importância do estudo feito também para o Aluno 10 sobre esses dois âmbitos.

Além disso, em alguns momentos, a estudante não demonstrou conhecimentos compatíveis com a ciência no que se refere ao conceito de trabalho, à sua formulação matemática e ao uso da mesma, como ocorreu na parte final da questão de 2014 e na questão de 2016. Como, em sua entrevista, ela acredita saber sobre esses conhecimentos, duas inferências podem ser feitas: ou a aluna não sabe reconhecer aquilo que realmente sabe, o que indica que ela precisa se desenvolver mais no que se refere ao conhecimento metacognitivo sobre pessoas, ou aquilo que a aluna acredita saber não é compatível com o conhecimento científico escolar. 


\section{Considerações finais}

Nesta pesquisa, investigou-se como a atividade denominada "Elaboração e resolução reflexivas de questões pelos estudantes", realizada em 2014, 2015 e 2016 por alunos de Ensino Técnico Integrado ao Ensino Médio de uma instituição federal de ensino, influenciou no desenvolvimento da metacognição dos mesmos. Para tanto, foi feita uma pesquisa qualitativa, por intermédio de entrevistas a estudantes que foram selecionados considerando seu desempenho na atividade nos três anos e os assuntos de física abordados por eles em suas questões.

Com base nos relatos do Aluno 10, percebe-se que ter feito a atividade em 2014 ajudou-o a realizá-la com mais facilidade em 2015, demonstrando que conhecer os critérios da tarefa solicitada, desenvolvendo o conhecimento metacognitivo sobre tarefas, parece ser importante para seu sucesso nela. No entanto, mesmo com o conhecimento sobre os critérios da tarefa, a presença do conhecimento abordado na questão é também um elemento central na realização da mesma, evidenciando que os aspectos cognitivos e metacognitivos parecem constituir de forma indissociável a realização da atividade proposta.

Ainda considerando a análise do Aluno 10, suas percepções sobre seu desempenho na atividade ao longo dos três anos não foram compatíveis com o seu desempenho real nela, o que pôde ser observado comparando-se os dois gráficos. Diante desse fato, é possível considerar que o indivíduo pôde transformar as suas percepções sobre seus processos cognitivos ao longo do tempo (o que pode ser um indicador de desenvolvimento da metacognição) ou que, mesmo que já tivesse tais percepções, o aluno conseguiu ter um bom desempenho na tarefa nos três anos por intermédio de estratégias e de relações que não explicitou.

Assim, concordamos com Maximo-Pereira e Andrade (2012, p. 663) quando afirmam que "a relação entre aquilo que o sujeito conhece e aquilo que ele sabe sobre o que conhece, ou seja, entre cognição e metacognição, permite que nos aproximemos do problema concreto que é saber como as pessoas aprendem".

Ao analisar a Aluna 32, ela apresentou dificuldade de elaborar questões envolvendo determinado conteúdo, no âmbito do conhecimento metacognitivo sobre tarefas, por mais que possa ter se apropriado do assunto. Isso é uma evidência de que o domínio do conteúdo não necessariamente implica no domínio da tarefa de elaborar uma questão sobre esse tema.

Como ela afirmou ter gostado do assunto que abordou em sua questão em 2014 e em 2016, mas obteve QI nos dois anos, o desempenho de um aluno na tarefa de elaborar e resolver questões parece não necessariamente ser compatível com o nível de interesse pelo assunto abordado expresso pelo estudante.

Sobre as relações afetivas positivas, foi possivel inferir que elas foram estabelecidas com a professora e com as situações de sala de aula, no caso do Aluno 10. No caso da Aluna 32, entendemos que ela expressou uma relação afetiva positiva com o conhecimento diretamente, sem nenhuma menção àquilo que a levou a isso.

Por tudo isso, considerando-se a análise comparativa do Aluno 10 e da Aluna 32, podese concluir que a explicitação de relações afetivas positivas com as situações de sala de aula e com o professor forneceu evidências de desenvolvimento da metacognição. Já a identificação de relações afetivas positivas com o conhecimento diretamente, sem nenhum 
detalhamento adicional, não implicou em evidências de desenvolvimento metacognitivo. Esse resultado amplia as relações entre afetividade e metacognição já disponíveis na literatura (EFKLIDES, 2006) e aprofunda as pesquisas sobre a atividade "Elaboração e resolução reflexivas de questões pelos estudantes" iniciadas em trabalhos anteriores (CARVALHO; MAXIMO-PEREIRA, 2016).

\section{Referências}

ABIB, M. L. V. S. Avaliação e melhoria da aprendizagem de Física. In: Anna Maria Pessoa de CARVALHO, A. O.; MAXIMO-PEREIRA, M. A elaboração de questões de Física por estudantes de Ensino Médio. In: Encontro de Física 2016, 2016, Natal. Anais do Encontro de Física 2016. São Paulo: Sociedade Brasileira de Física, 2016. p. 1-8.

ARANTES, V. A. A afetividade na escola - Alternativas Teóricas e Práticas. São Paulo: Summus Editorial, 2003, p. 7-12.

CACHEFFO, V. A. F. F.; GARMS, G. M. Z. A afetividade nas produções do GT 20 (Psicologia da Educação) da ANPED. In: X CONGRESSO NACIONAL DA PSICOLOGIA ESCOLAR E EDUCACIONAL, 2011. Maringá. Anais do X Congresso Nacional da Psicologia Escolar e Educacional. Maringá: 2011.

CARVALHO, A. O.; MAXIMO-PEREIRA, M. A elaboração de questões de Física por estudantes de Ensino Médio. In: Encontro de Física 2016, 2016, Natal. Anais do Encontro de Física 2016. São Paulo: Sociedade Brasileira de Física, 2016. p. 1-8.

EFKLIDES, A. Metacognition and affect: What can metacognitive experiences tell us about the learning process? Educational Research Review. v. 1, p. 3-14, 2006.

FIGUEIRA, A. P. C. Metacognição. e seus contornos. Revista Iberoamericana de Educación (Online). 1-20, 2003.2 Disponível em: <http://www.rieoei.org/deloslectores/446Couceiro.pdf>. Acesso em: 03 jan. 2017.

FLAVELL, J. H. Metacognitive aspects of problem solving. In: RESNICK, L. B. (Org.). The nature of intelligence. Hillsdale, N.Y.: Lawrence Erlbaum Associates, 1976, p. 231-235.

FLAVELL, J. H.; Metacognition and cognitive monitoring. A new area of cognitivedevelopmental inquiry. American Psychologist, v. 34, n. 10, p. 906-911, 1979.

FLAVELL, J. H. Speculations about the nature and development of metacognition. In WEINERT, F. E.; KLUWE, R. H. (Org.). Metacognition, motivation and understanding. Hillsdale, N. Y.: Lawrence Erlbaum Associates, 1987. p. 21-29.

FLAVELL, J. H.; MILLER, H. P.; MILLER, S. A. Desenvolvimento cognitivo. Porto Alegre: Artmed, Trad. Claudia Dornelles, 1999. 341p.

GOMES, A. S. A.; ALMEIDA, A. C. P. C. Letramento científico e consciência metacognitiva de grupos de professores em formação inicial e continuada: um estudo exploratório. Amazônia Revista de Educação em Ciências e Matemática, v. 12, n. 24, p. 53-73, 2016.

HAGUETTE, T. M. F. Metodologias Qualitativas na Sociologia. Petrópolis - RJ: Editora Vozes, 11. ed, p. 86-105, 2007. 
MAHONEY, A. A.; ALMEIDA, L. R. Sentimentos e emoções: um estudo com professores do ensino superior. In: 28a Reunião Anual da ANPED, 2005, Caxambú. Anais... Caxambu: Anped, 2005. p. 1-7.

MÁRQUEZ, C.; ROCA, M. Plantear preguntas: un punto de partida para aprender ciencias. Revista Educación y Pedagogía. v. 18, n. 45, p. 61-71, 2006.

MAXIMO-PEREIRA, M. Memória mediada na aprendizagem de física: problematizando a afirmação "Não me lembro de nada das aulas do ano passado!". 2014. Tese (Doutorado em Ensino de Física) - Ensino de Ciências (Física, Química e Biologia), Universidade de São Paulo, São Paulo, 2014.

MAXIMO-PEREIRA, M.; ANDRADE, V. A. Autoavaliação como estratégia para o desenvolvimento da metacognição em aulas de ciências. Investigações em Ensino de Ciências, n. 17, p. 663-674, 2012.

MAXIMO-PEREIRA, M.; ANDRADE, V. A. Elaboração e resolução de questões pelos estudantes: um estudo de caso acerca de aspectos cognitivos e metacognitivos. Ensino, Saúde e Ambiente, v. 7, p. 1-13, 2014.

MOREIRA, H.; CALEFFE, L. G. Metodologia da pesquisa para o professor pesquisador. 2. ed. Rio de Janeiro: Lamparina, 2008. 245 p.

PASSOS, M. M.; CORRÊA, N. N. G.; ARRUDA, S. M. Perfil Metacognitivo (Parte I): Uma proposta de instrumento de análise. Investigação em Ensino de Ciências, v. 22, n. 3, p. 176191, 2017.

RIBEIRO, C. Metacognição: Um Apoio ao Processo de Aprendizagem. Psicologia: Reflexão e Crítica, v. 16, n. 1, p. 109-116, 2003.

ROSA, C. T. W.; PINHO-ALVES, J. Evocação espontânea do pensamento metacognitivo nas aulas de Física: estabelecendo comparações com as situações cotidianas. Investigações em Ensino de Ciências, v. 17, n. 1, p. 7-19, 2012.

VIGOTSKI, L. S. A construção do pensamento e da linguagem. 2. ed., São Paulo: WMF Martins Fontes, 2009. 